\title{
Efficacy of Small Molecule Phytochemicals of Petroleum Ether Pod Extract of Prosopis cineraria (L.) Druce on HMG-CoA Reductase and Biomarker Indices of Lipoproteins: In-vitro, In-vivo and In-silico Study
}

\author{
Heera Ram ${ }^{1, *}{ }^{\mathbb{D}}$, Noopur Jaipal ${ }^{1}$, Jaykaran Charan $^{2}$, Priya Kashyap ${ }^{3}$, Suresh Kumar ${ }^{3}$ \\ 1 Department of Zoology, Jai Narain Vyas University, Jodhpur (Rajasthan)-342001, India \\ 2 Department of Pharmacology, All India Institute of Medical Sciences, India \\ 3 University School of Biotechnology, Guru Gobind Singh Indraprastha University, Dwarka, Sector 16C New Delhi, India \\ * Correspondence: hr.zo@jnvu.edu.in (H.R.);
}

Scopus Author ID: 21234209400

Received: 5.06.2021; Revised: 7.07.2021; Accepted: 12.07.2021; Published: 8.08.2021

\begin{abstract}
The assigned goals of the study were examined to HMG-CoA reductase inhibition and antioxidants potential of the small molecule phytochemicals of petroleum ether pod extract of Prosopis cineraria (L.) Druce by in-vitro, in-vivo, and in-silico assessments. The phytochemical fingerprinting of the extract was done by LC-MS analysis, and compounds were identified using mass hunter software. In-vitro HMG-CoA reductase assay performed by sigma Aldrich kit. According, in-vivo investigations were conducted by using a hypercholesterolemic rabbit animal model. Further, in-silico analyses of molecular docking and ADMET were conducted by standard protocol. The leading identified compounds, i.e., prosogerin-A, luteolin, and gallic acid, were docked with the target enzyme of HMGCoA reductase, which demonstrated significant binding energies up to -7.2 to $8.1(\mathrm{Kcal} / \mathrm{mol})$. Subsequently, the ADMET predictions revealed druggability and ideal pharmacokinetics profile. Accordingly, the in-vitro HMG-CoA reductase inhibition assay was showed 53.1\% inhibition capability of the test extract. The in-vivo investigation shown that the test extract caused significant reductions in the atherogenic index (log (Total cholesterol/triglyceride), Castelli risk index-I (CRI-I), and Castelli risk -II(CRI-II) along with lipid profile and antioxidants levels. It can be concluded that small-molecule phytochemicals such as Prosogerin A, Luteolin, Gallic acid are present in petroleum ether pod extract of Prosopis cineraria (L.) Druce possesses the capability to subside hypercholesterolemia and ameliorations in biomarker lipoproteins indices through HMG-CoA reductase inhibition and antioxidant potential.
\end{abstract}

Keywords: hypercholesterolemia; HMG-CoA reductase; lipoprotein indices; small molecule phytochemicals; lipoprotein indices; molecular docking.

(C) 2021 by the authors. This article is an open-access article distributed under the terms and conditions of the Creative Commons Attribution (CC BY) license (https://creativecommons.org/licenses/by/4.0/).

\section{Introduction}

The natural products can ameliorate several metabolic disorders by synchronizing several phytochemicals in this herbal extract. The scientific explanation regarding therapeutic efficacy is limited due to their solubility and bioavailability at target sites[1,2]. Accordingly, the different extracts of the same plant present variable efficacy due to the different solubility shown by various phytochemicals. The solubility of phytochemicals depends on the functional groups' polarity or availability, which indicates the reactivity of the compounds or groups of compounds (extracts)[3,4]. Accordingly, the traditional medicines and the Ayurvedic 
formulations are using different kinds of oily or aqueous suspensions for therapeutics of several ailments, which indicates the hydrophobic and hydrophilic nature of exhibited phytochemicals[5,6]. Consequently, the traditional food of panchkuta (polyherbal formulation of local herbs) of the western Rajasthan, specifically widely used in the local occasion of the sheetalasaptmi (transitional phase of winter and summer), which is known as the basoda prepared in aqueous suspension with oil fry by logical of obtaining the hydrophilic compounds with hydrophobic compounds. The pod of Prosopis cineraria (L.) Druce is a key component of the traditional food recipe of the panchkuta used by local people from long back based on transmitted traditional knowledge[7,8]. The Prosopis cineraria (L.) Druce pod has unique phytochemicals due to the biosynthesis of these kinds of metabolites influenced by temperature stress conditions. Accordingly, our previous studies revealed the potential of phytochemicals of an ethanolic extract of Prosopis cineraria (L.) Druce pod ameliorates cardiovascular diseases by inhibiting HMG-CoA reductase inhibition and showing dual inhibition of DPP-4 and cholinesterase, which improve neurological impairment in the diabetic animal model. Several studies also reported this [9-11]. Subsequently, there are several researchers who reported pharmacological and medicinal values of Prosopis cineraria which validates its uses in traditional or folk medicines. Therefore, the recent study was aimed to assess the potential of phytochemicals of petroleum ether extract of Prosopis cineraria (L.) Druce pod in hypercholesterolemia for therapeutics by in-vitro, in-vivo, and in-silico investigations.

\section{Materials and Methods}

\subsection{Collection and extraction of plant material.}

The pods of Prosopis cineraria (L.) Druce is commonly used for the traditional food recipe of the panchkuta, which is easily available at the provisional store were obtained from the local provisional store and processed for drying, grinding, and extraction procedures. The petroleum ether for non-polar extract proceeded by following the standard procedure of soxhlet extraction below the solvent's boiling temperature as per the routine method [12].

\section{2. $L C-M S$ analysis of the test extract.}

The test extract of the petroleum ether extract was screened by using LC-MS composed of LCMS-IT-TOF and suitable column equipped with ESI-source by following the standard protocol of APCI (Atmospheric pressure chemical ionization) [13-15]. Each platform was equipped with a binary solvent delivery unit, a degasser, an auto-sampler, and a column oven. MS data was composed in scan mode of range 50-1200 m/z with both positive and negative polarities included. Default determination settings were chosen for both platforms. Accordingly, the sample proceeded by a routine ionization process of APCI, and peaks of leading compounds were obtained. The obtained data were proceeded for identification of obtained peaks by using mass hunter software.

\subsection{Administration of extract and atorvastatin.}

The test extract was given oral guava at the dose of $400 \mathrm{mg} / \mathrm{kg} / \mathrm{per}$ day for experimentation, and the atorvastatin (atorlip@20mg) dose was calculated as per human subject [16]. 


\subsection{In-vitro HMG-CoA reductase assay.}

The HMG-CoA reductase inhibition potential of the test was performed using ascending concentrations gradient compared to the standard drug (pravastatin) provided in the Sigma Aldrich assay kit for in-vitro assessment by following the protocol $[15,17,18]$. The ascending concentration assays of samples of the test extract and drug were analyzed spectrophotometrically at $340 \mathrm{~nm}$. The chromophore was characterizing the oxidation of NADPH by the catalytic subunit of HMGR in the presence of the substrate HMG-CoA.

\subsection{Experimental design.}

The experimental design comprised four groups compared to control and treatment. Each group contains seven animals as per permitted protocol of the institutional animal ethics committee (IAEC) as per the standard norms of CPCSEA (Reg. No.1646/GO/a/12/CPCSEA valid up to 27.03.23). The adult healthy male rabbits were used as an animal model of hypercholesterolemia, which was kept under optimal controlled environmental conditions. Experimentations were scheduled for 60 days included hypercholesterolemia induction and treatments of test extract (45days).

The experimental design was comprised of the following four groups.

Group A: Vehicle control: received only vehicle.

Group B: Hypercholesterolemic control: Animals were fed with a high-fat diet and cholesterol powder supplementation.

Group C: Treatment group of petroleum ether pod extract of Prosopis cineraria (L.) Druce.

Group D: Treatment group of the standard drug (Atorvastatin).

\subsection{Development of hypercholesterolemic animals.}

The development of hypercholesterolemia in the animal model was followed by a highfat diet along with cholesterol powder supplementation as per modified protocol through diet induction by standard methods[19-21]. The course of hypercholesterolemia was made for 1520 days through formulated high-fat diet along with $500 \mathrm{mg}$ supplementation of cholesterol powder per day for the schedule. The confirmation of the development of hypercholesteremia was made by evaluating lipid profiles and calculations of marker biomarker lipoproteins indices.

\subsection{Obtaining samples for biochemical investigations.}

The samples of serum biochemistry were collected after the completion of experiments from autopsied 24 hours fasted animals by following standard procedure. The blood was collected in EDTA coated and non-coated vials from the hepatic vein and direct cardiac puncture. The plasma was separated by centrifugation at $3000 \mathrm{rpm}$ for 15 minutes[22].

\subsection{In-vivo investigations: total protein, lipid profile, and marker biomarker lipoproteins} indices.

The biochemical examination of total protein [23], total cholesterol [24], triglyceride [25], and HDL-cholesterol [26] were analyzed by following suitable methods. Subsequently, lipid profile and marker biomarker lipoprotein indices, i.e., atherogenic index (Log 
(Triglyceride / HDL-cholesterol) [27], Castelli risk index - I (Total cholesterol/HDL) [28], and Castelli risk index - II (LDL/HDL) [28] were calculated by standard calculations.

\subsection{In-vivo investigations of antioxidants and peroxidation levels of serum.}

The serum antioxidant levels were measured in control as well as treatment groups by following standard protocols [29] of total antioxidant by FRAP assay (Ferric Reducing Antioxidant Potential) [30], superoxide dismutase (SOD) [31], GSH (reduced glutathione) and catalase [33]. Subsequently, the thiobarbituric acid reactive substances (TBARS) and malondialdehyde (MDA) contents were examined for lipid peroxidation (LPO) [34].

\subsection{In-silico analysis of molecular docking.}

Molecular interactions of identified small molecule phytochemicals with HMG-CoA reductase were analyzed by using Autodock 4.2 [35,36]. The human HMG-CoA reductase (1HW8) catalytic part was obtained from a protein data bank and processed using PyMol to extract a co-crystallized ligand inhibitor, eliminate unwanted water molecules, and correct for chain integration. Three-dimensional structures of identified compounds and known inhibitors (pravastatin and atorvastatin) were obtained from PubChem Database. Ligand processing was performed using PyMol, and hydrogen was added to the structures. The docking protocol developed was validated by performing re-docking with prepared co-crystallized ligand and organized receptor protein, and the maps were produced. Post validation of the docking protocol of identified small molecule phytochemicals was independently docked with target receptor proteins in the study. Molecular interactions, ligand conformations, and binding energies were obtained.

\subsection{ADMET (Absorption, Distribution, Metabolism, Excretion, and toxicity) analysis.}

ADMET analysis of identified small molecule phytochemicals was carried out using Drulito software to study the ideal pharmacokinetic profile to assess druggable properties[35,37]. The compounds were screened based on two filters, the Lipinski rule and the blood-brain barrier (BBB). Lipinski rule states that an ideal drug molecule should weigh below $500 \mathrm{~g} / \mathrm{mol}$, hydrogen bond donor should be less than or equal to 5 , and the number of hydrogen bond acceptor should be less than or equal to 10 along with a partition coefficient of 5 or less. Such compound would pass BBB if the number of hydrogen bonds present is between $8-10$, and there should not be any acidic group present in the molecule. TPSA (total polar surface area) showed bioavailability of the drug molecule; as per Veber's rule, the TPSA less than or equal to $140 \AA$ indicates good oral bioavailability.

\subsection{Statistical analysis.}

All data were analyzed and expressed as a mean \pm SEM (standard error of the mean). Graphical representations of the data were constructed using MS Excel 2018 by following the one-way ANOVA through multiple variances [38]. 


\section{Results}

\subsection{LC-MS analysis of petroleum ether pod extract of Prosopis cineraria (L.) Druce.}

The LC-MS data were scrutinized by Masshunter software developed by Agilent with obtained peaks of leading small molecule phytochemicals. The generated peaks in both positive and negative modes of ionization above $\geq 3000$ ionization counts were considered with the tolerance of peak spacing $0.0080 \mathrm{~m} / \mathrm{z}$ for sensible resolution of the chromatogram. Chromatogram peaks were assigned masses based upon the MS-MS fragmentation pattern specific for the identified leading small molecule phytochemicals. Mass Bank workstation software along with a literature database was obtained for the evaluation of metabolite profile. The results were represented according to the monoisotopic mass of identified compounds (Table 1; Figure 1A and Figure 1B).

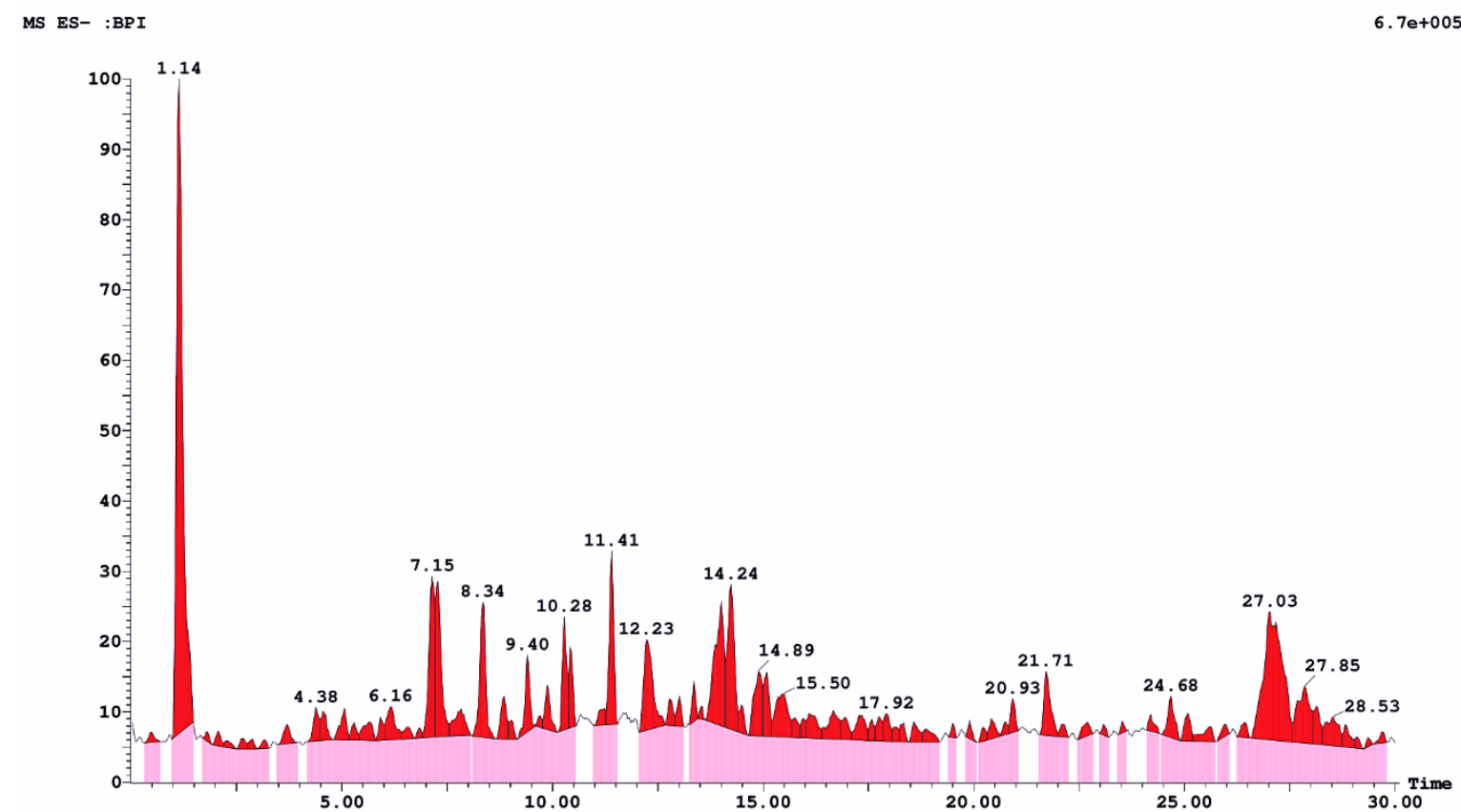

Figure 1A. QTOF (LC-MS) chromatograph of petroleum ether pod extract of Prosopis cineraria (L.) Druce.

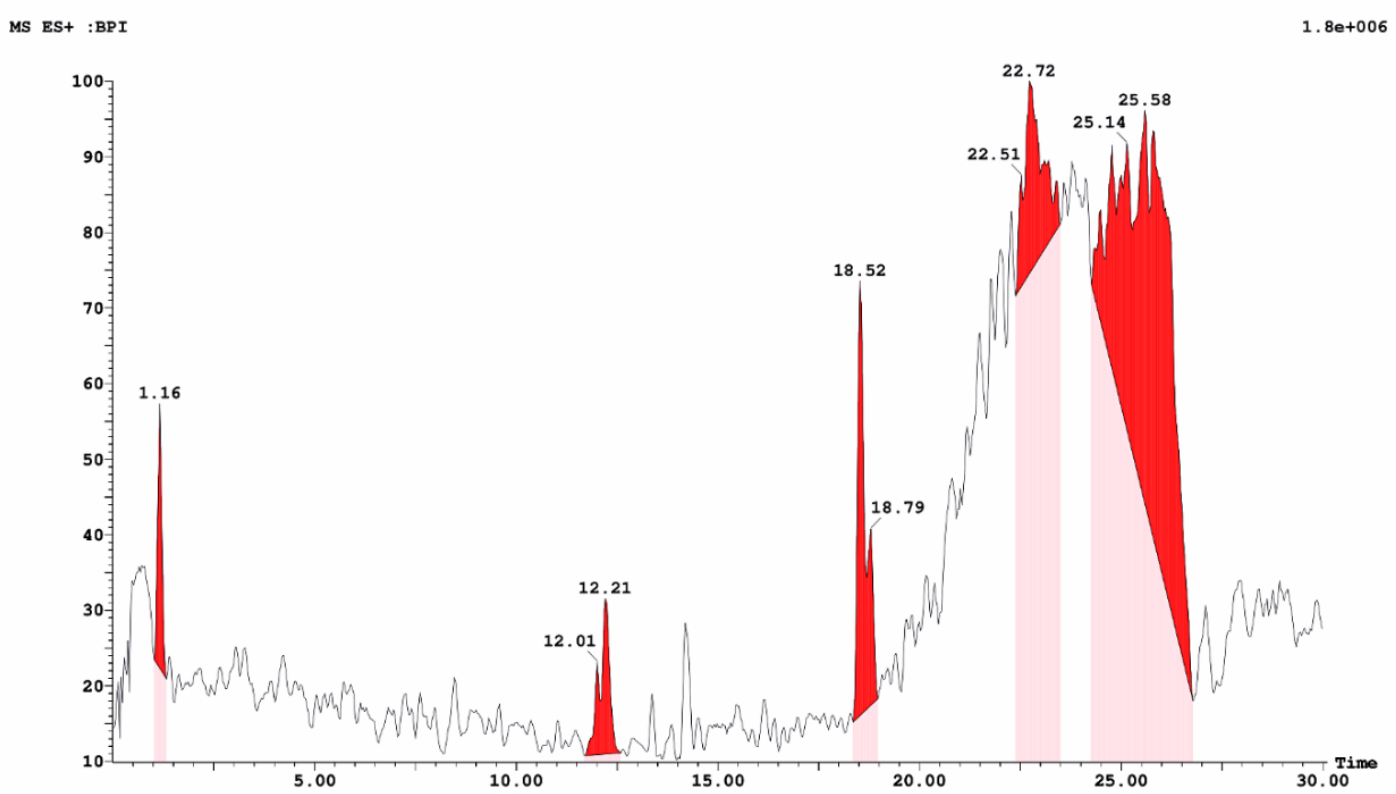

Figure 1B. QTOF (LC-MS) chromatograph of petroleum ether pod extract of Prosopis cineraria (L.) Druce. 
Table 1. Identified masses from UPLC-QTOF mass spectroscopy constituents in Prosopis cineraria's petroleum ether pod extract (L.) Druce in negative electron ionization mode.

\begin{tabular}{l|l|c|c|c|c} 
S.No. & $\begin{array}{l}\text { Identified compounds of } \\
\text { the test extract }\end{array}$ & Formula & $\begin{array}{l}\text { Monoisotopic mass } \\
\text { (g/mol) }\end{array}$ & $\begin{array}{l}\text { Retention time } \\
(\mathbf{m i n})\end{array}$ & m+z values \\
\hline 1. & Prosogerin A & $\mathrm{C}_{17} \mathrm{H}_{12} \mathrm{O}_{6}$ & 312.27 & $14 \mathrm{~min}$ & 311.2 \\
\hline 2. & Luteolin & $\mathrm{C}_{15} \mathrm{H}_{10} \mathrm{O}_{6}$ & 286.05 & $13.01 \mathrm{~min}$ & 287.2 \\
\hline 3. & Gallic acid & $\mathrm{C}_{7} \mathrm{H}_{6} \mathrm{O}_{5}$ & 170.02 & $1.79 \mathrm{~min}$ & 146.9
\end{tabular}

3.2. In-vitro assay of HMG-CoA reductase inhibition potential.

The in-vitro assay of test extract was performed compared to the standard drug (Pravastatin, provided in assay kit) as per ascending concentrations which was a maximum of $53.1 \%$ at the concentration of $5 \mu \mathrm{g} / \mathrm{ml}$ (Figure $2 \mathrm{~A}$ and $2 \mathrm{~B}$ ).

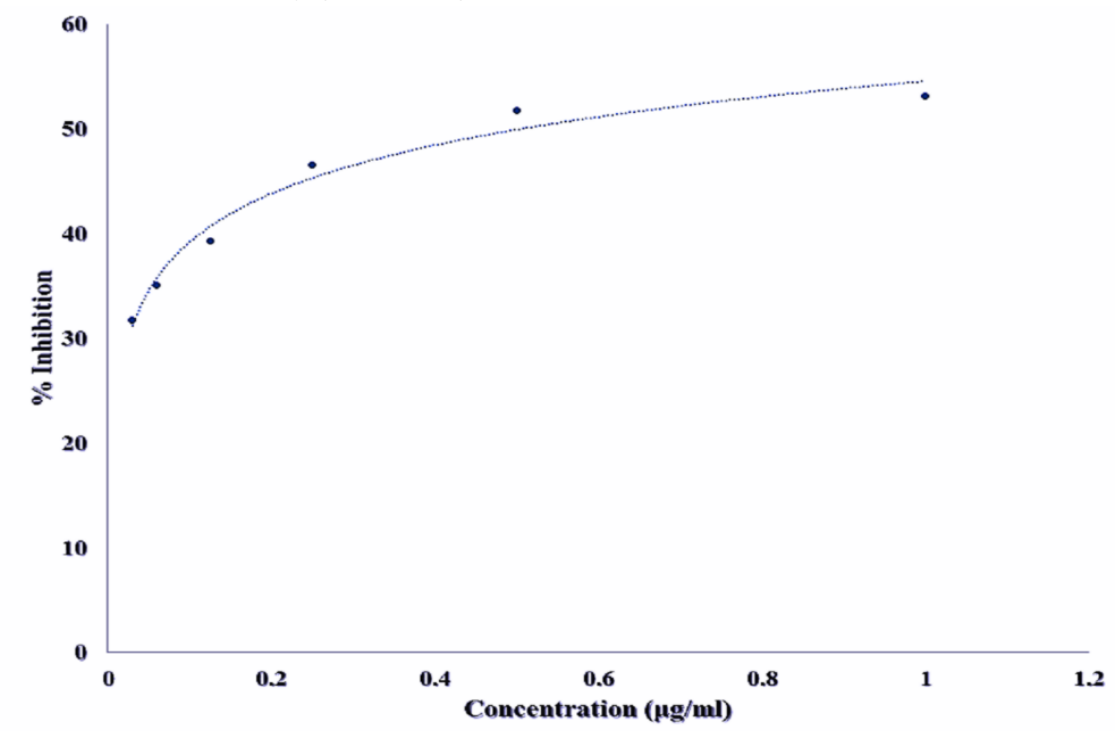

Figure 2A. HMG-CoA reductase inhibition potential of pravastatin (Equation- $\mathrm{y}=2.978 \ln (\mathrm{x})+95.448, \mathrm{R}^{2}=$ $0.9751, \mathrm{IC} 50=0.03 \mu \mathrm{M})$

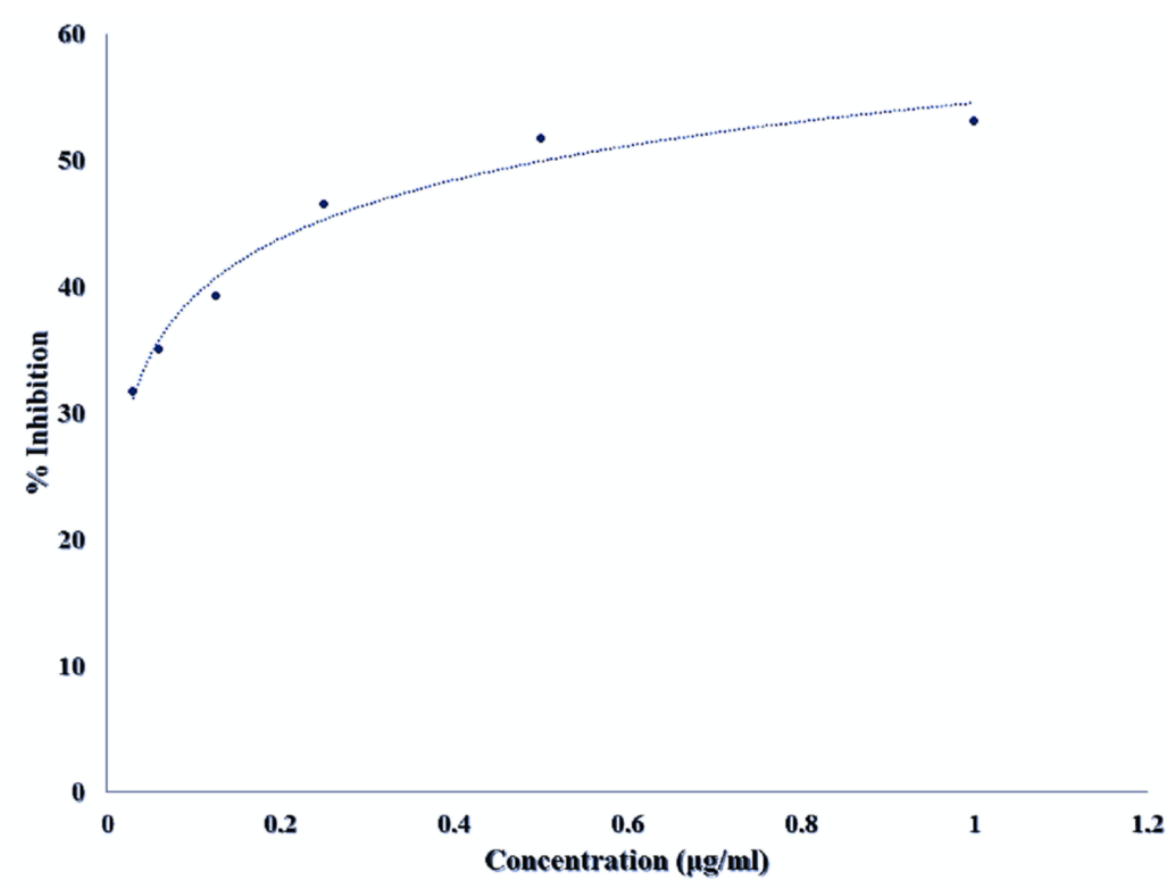

Figure 2B. HMG-CoA reductase inhibition potential of the test extract (Equation- $y=6.6709 \ln (\mathrm{x})+54.551, \mathrm{R}^{2}$ $=0.9763, \mathrm{IC} 50=0.5 \mu \mathrm{g} / \mathrm{ml}$ ) 
3.3. Alterations in biomarker lipoprotein indices (Atherogenic index, Castelli-I \& II) and lipid profile.

The treatment of test extract caused significant $(\mathrm{P} \leq 0.001)$ alterations in the atherogenic index where atherogenic index $=\log$ (Triglyceride / HDL-cholesterol), Castelli risk index $-\mathrm{I}$ (Total cholesterol/HDL) and Castelli risk index - II (LDL/HDL), along with lipid profile parameters of total cholesterol, triglyceride, LDL-cholesterol and VLDL-cholesterol. The total cholesterol and biomarker lipoprotein indices were increased around ten folds in hypercholesterolemia (Figure 3 and Figure 4).

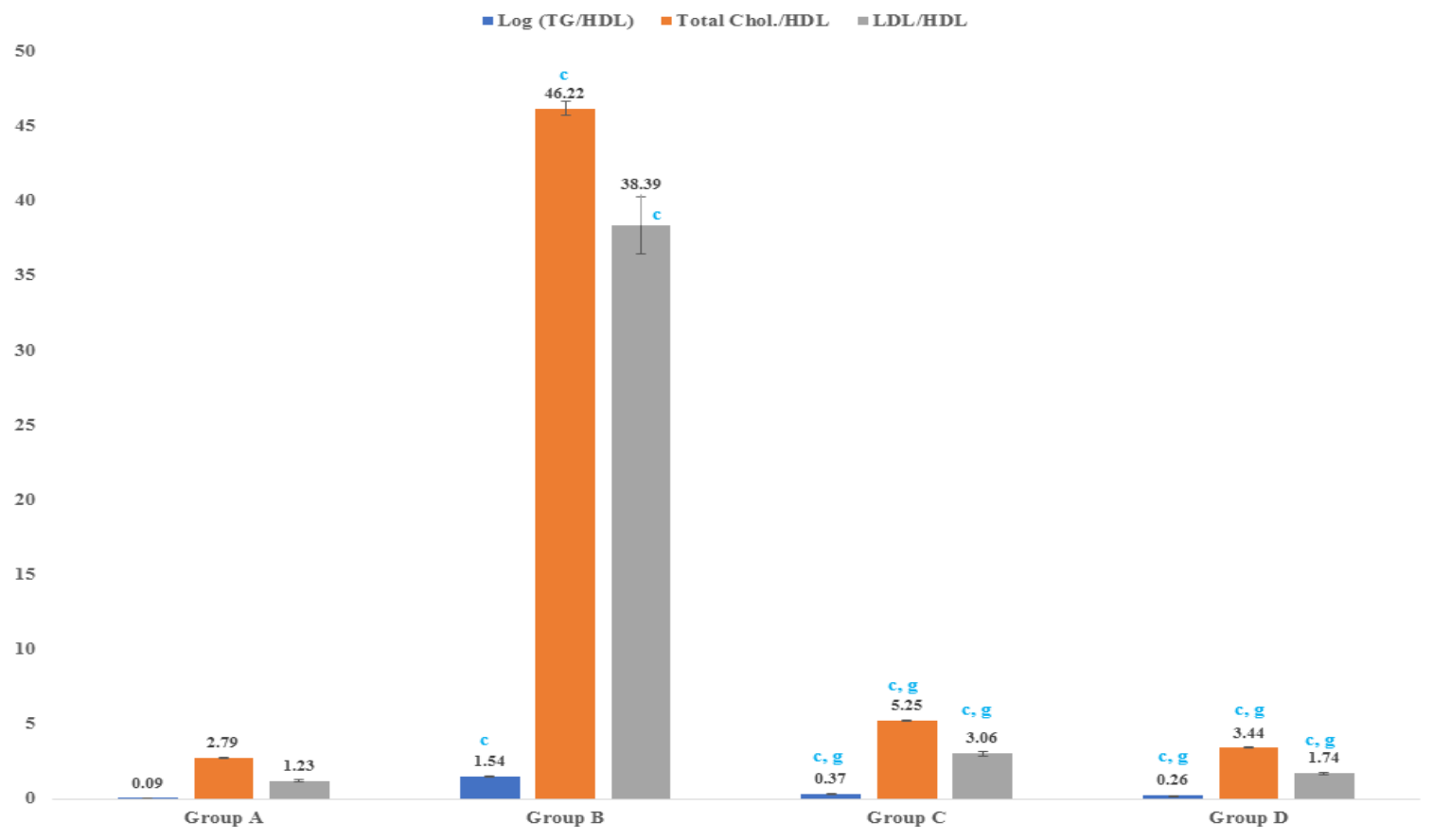

Figure 3. Effect of phytoconstituents of petroleum ether pod extract of Prosopis cineraria (L.) Druce on abnormal lipoprotein ratios (Atherogenic index and Castelli indexes - I \& II).

1200

-Group A $=$ Group B $=$ Group C $=$ Group D

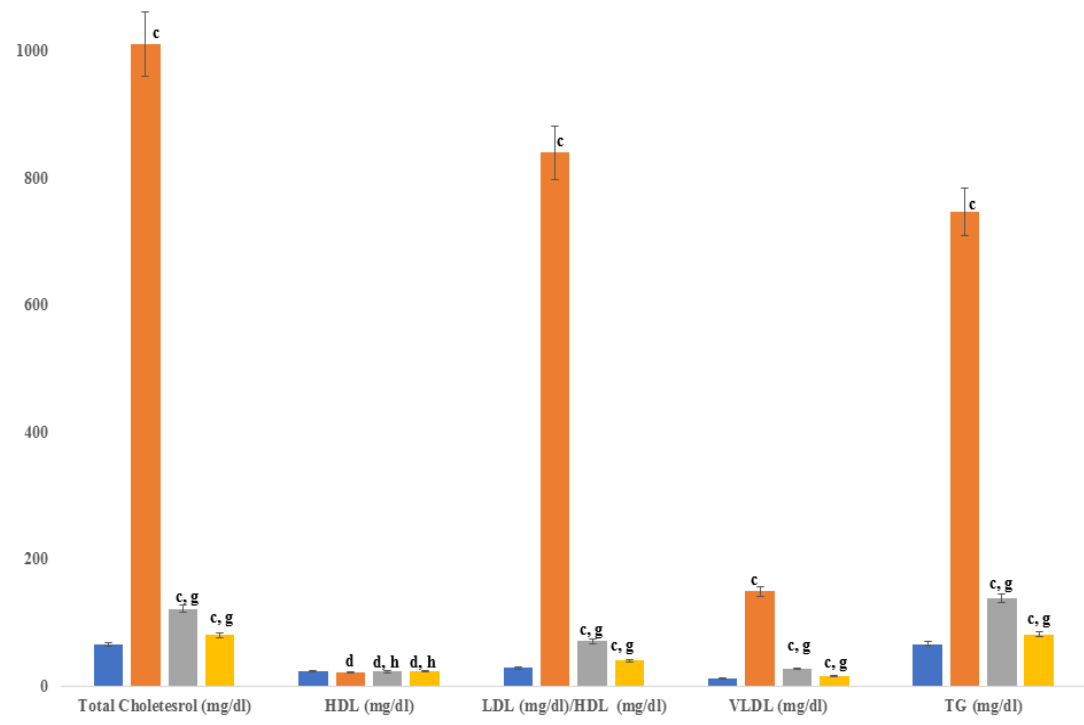

Figure 4. Effect of phytoconstituents of petroleum ether pod extract of Prosopis cineraria (L.) Druce on lipid profile. 


\subsection{Fluctuations in antioxidants levels and lipid peroxidation.}

The total antioxidants, catalase, superoxide dismutase (SOD), and glutathione (GSH) levels were significantly $(\mathrm{P} \leq 0.001)$ reduced in hypercholesterolemia. Subsequently, the lipid peroxidation was increased significantly. The treatment of test extract caused a significant $(\mathrm{P} \leq$ 0.001) reduction. Accordingly, the test extract caused significant improvements in levels of SOD, catalase, GSH, and total antioxidants (FRAP) (Figure 5).

-Group A $\|$ Group B $\|$ Group C $\backsim$ Group D

600

500

400

300

200

100

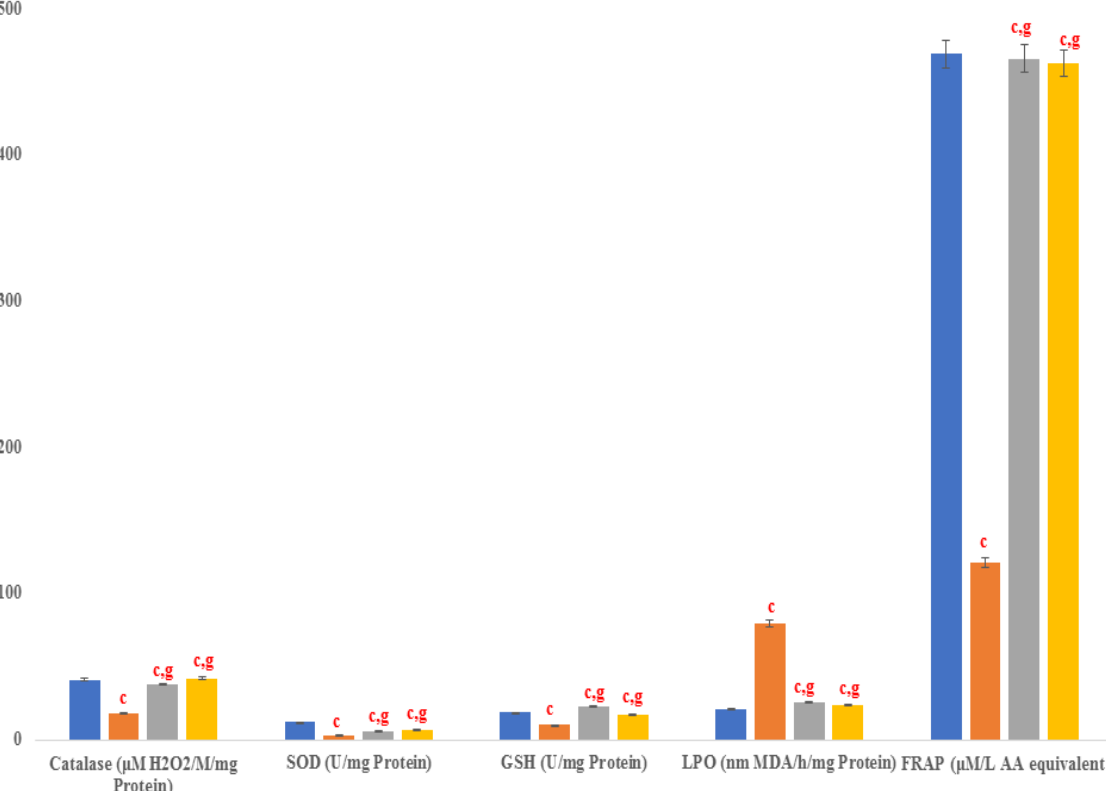

Figure 5. Effect of phytoconstituents of petroleum ether pod extract of Prosopis cineraria (L.) Druce on antioxidants.

\subsection{Molecular docking.}

HMG-CoA has a catalytic grove consisting of residues from 426 to 888 . The catalytic portion is composed of Cys688, Thr689, Asp690, and Lys691. The side chain of Lys691 positioned itself in the middle of the active site. The flap consisting mainly of Glu559 and Asp767 is in the front of the active site. As evident from the table, all the identified small molecule phytochemicals interacted with the main catalytic site residues with strong binding energies thus inhibiting the protein irreversibly (Table 2).

Table 2. Molecular docking of small-molecule phytochemicals of petroleum ether pod extract of Prosopis cineraria (L.) Druce against HMG-CoA reductase

\begin{tabular}{|c|c|c|c|c|c|}
\hline S. No. & $\begin{array}{l}\text { Ligand (Standard drugs } \\
\text { and key identified } \\
\text { phytocompounds) }\end{array}$ & $\begin{array}{l}\text { Binding Energy } \\
\text { (Kcal/mol) }\end{array}$ & No. of H-bonds & Bond length $(\AA)$ & $\begin{array}{l}\text { Interacting } \\
\text { residues }\end{array}$ \\
\hline \multicolumn{6}{|c|}{ Standard Drugs (Positive Control) } \\
\hline 1. & Pravastatin & -7.0 & 2 & $1.8,2.1$ & $\begin{array}{l}\text { Asp690, } \\
\text { Lys691 }\end{array}$ \\
\hline 3. & Atorvastatin & -7.8 & 1 & 2.2 & Asp690 \\
\hline \multicolumn{6}{|c|}{ Dominating phytoconstituents of the extract } \\
\hline 4. & Prosogerin A & -7.9 & 3 & $3.3,2.2,3.4$ & $\begin{array}{l}\text { Val805, } \\
\text { Gly560, } \\
\text { Gly } 765 \\
\end{array}$ \\
\hline 5. & Luteolin & -8.1 & 5 & $2.4,2.9,2.5,(2.1$, & Ala751, \\
\hline
\end{tabular}




\begin{tabular}{l|l|l|l|l|l} 
S. No. & $\begin{array}{l}\text { Ligand (Standard drugs } \\
\text { and } \\
\text { phytocompounds) }\end{array}$ & $\begin{array}{l}\text { Binding Energy } \\
\text { (Kcal/mol) }\end{array}$ & No. of H-bonds & Bond length (Å) & $\begin{array}{l}\text { Interacting } \\
\text { residues }\end{array}$ \\
\hline & & & & $2.2)$ & $\begin{array}{l}\text { Cys561, } \\
\text { Gly560, } \\
\text { Lys692 }\end{array}$ \\
\hline 6. & Gallic acid & -7.2 & 3 & $2.7,(2.4,2.4)$ & $\begin{array}{l}\text { Gly806, } \\
\text { Gly808 }\end{array}$
\end{tabular}

The table shows the binding energies obtained with identified small molecule phytochemicals along with standard drugs (Atorvastatin and pravastatin) showed stronger binding energies than pravastatin used as a positive control in the study. Gallic acid does not show any interaction with main catalytic site residues but occupies the catalytic site. Luteolin showed dual hydrogen bonds with main catalytic site residue Lys692 while orienting itself to occupy the complete catalytic groove. Also, the molecular interaction of these compounds with catalytic site residues by hydrogen bond formation was evident in docking analysis (Figure 6A6C).

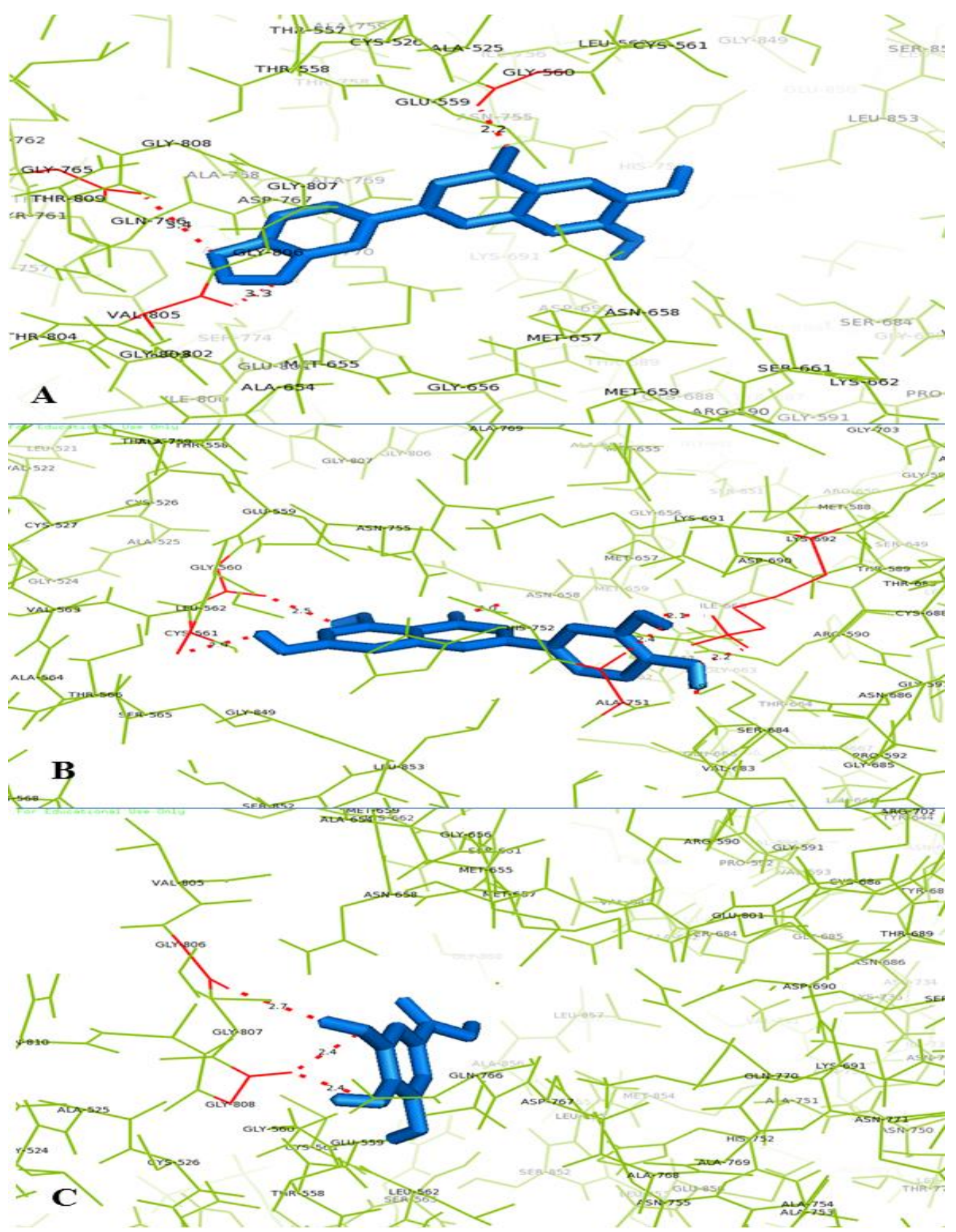


Figure 6. Molecular interactions of identified compounds studied using docking analysis; (A)- HMG-CoA interaction with prosogerin A; (B)- HMG-CoA interaction with luteolin; (C)- HMG-CoA interaction with gallic acid.

\subsection{Pharmacokinetics.}

ADMET studies of identified small molecule phytochemicals showed that Prosogerin A is the only compound that obeys the Lipinski rule of five along with the potential to cross BBB amongst identified small molecule phytochemicals. Though gallic acid and luteolin have smaller molecular sizes, gallic acid has one acidic group in its chemical structure, and luteolin has the exceeding number of hydrogen bonds. Therefore, they probably show less potential to cross BBB but obey the Lipinski rule of five for ideal drug molecules (Table 3).

Table 3. Pharmacokinetics ADMET of small molecule phytochemicals of petroleum ether pod extract of Prosopis cineraria (L.) Druce prediction by Drulito against Lipinski rule of five and blood-brain-barrier filter.

\begin{tabular}{|c|c|c|c|c|c|c|c|c|c|}
\hline $\begin{array}{l}\text { Dominating compounds of } \\
\text { the test extract }\end{array}$ & MW & $\log \mathrm{P}$ & $\mathrm{A} \log \mathrm{P}$ & HBA & HBD & TPSA & nHB & $\begin{array}{l}\text { nAcidic } \\
\text { group }\end{array}$ & Filter L/B \\
\hline Prosogerin A & 312.06 & 1.947 & -0.793 & 6 & 1 & 74.22 & 7 & 0 & $\mathrm{~L} / \mathrm{B}$ \\
\hline Luteolin & 286.05 & 1.486 & -0.787 & 6 & 4 & 107.22 & 10 & 0 & $\mathrm{~L}$ \\
\hline Gallic acid & 170.02 & 0.964 & -0.721 & 5 & 4 & 97.99 & 9 & 1 & $\mathrm{~L}$ \\
\hline
\end{tabular}

\section{Discussion}

The presence of several secondary metabolites of the plants in the form of phytochemicals is chemically transformed during metabolism responsible for various medicinal activities $[3,39,40]$. Contrasting genes and proteins, whose purpose is subject to the epigenetic directive and post-translational alterations correspondingly, metabolites or small molecule phytochemicals attend as signatures of biochemical activity. They are therefore easier to associate with phenotype $[41,42]$. In this context, metabolite profiling, or metabolomics, has developed a powerful method extensively espoused for clinical diagnostics. Accordingly, the LC-MS analysis of the test extract showed some leading compounds that were performed their potential to ameliorate hypercholesterolemia by following several mechanisms. Accordingly, the in-vitro assessment of the test extract shown significant inhibition of HMG-CoA reductase, which indicates the subside of cholesterol biosynthesis as per the mechanism of statins $[43,44]$. The enzyme HMG-CoA (3-hydroxy-3-methylglutaryl-coenzyme A) reductase is the key enzyme in cholesterol biosynthesis that catalyzes HMG-CoA conversion to mevalonate. The inhibition of HMG-CoA reductase efficiently reduces cholesterol by activating sterol regulatory element-binding protein-2(SREBP-2), which upregulates the HMG-CoA reductase and LDL receptor that leads to the reduction of cholesterol levels $[45,46]$. Supportively, numerous studies and our previous reports illustrated that small-molecule phytochemicals can inhibit enzymatic activities of HMG-CoA reductase by following several mechanisms $[10,47,48]$. Accordingly, in-silico analysis shown the compatibility between the active sites of target enzyme and functional parts of leading compounds as ligands which resulted in HMGCoA reductase inhibition[49]. The in silico study demonstrated that ligand-protein interface study in which test compound binds to (HMG-CoA) in the catalytic domain may form 
hydrogen bonds, electrostatic interactions, and hydrophobic interactions with the residues at the binding site [50]. Furthermore, the ADMET predictions showed the druggability properties of test compounds [50]. Besides this, hypercholesterolemia is marked by biomarker lipoprotein indices and elevated lipid profile, indicating the irregular circulation and biosynthesis of cholesterol [51]. The fractional esterification is one of the key markers of reverse cholesterol transport, which is hampered by the improper packaging of lipoproteins depicted in the biomarker logarithm of the triglyceride /HDL-cholesterol ratio (atherogenic index) [52,53]. Further, characterized by the elevated levels of the biomarker indices of lipoproteins, i.e., Catelli index -I (Total cholesterol /HDL) and Castelli index -II (LDL/HDL), which indicates the irregular packaging and esterification of lipoproteins [27,54]. Whereas the treatment of the test extract caused significant improvements in the atherogenic index as well as the Castelli indexes, which indicates the reversal of the states of the lipoproteins packaging by proper esterification and normalcy in reveres cholesterol transport as reported by several studies that small molecules phytochemicals have capacities to restore the proper biosynthesis of lipoproteins and regulation of reverse cholesterol transport [55-57]. Supportively, the treatment of the test extracts shown significant alterations in enzymatic antioxidants such as catalase, superoxide dismutase, glutathione, and total antioxidants, as well as lipid peroxidation, which indicates the free radical scavenging potential of phytochemicals of the extract [54,58,59]. Whereas hypercholesterolemia was represented by the elevated and improper levels of the antioxidants as well as lipid peroxidation due to generations of free radicals from deterioration activities $[9,60,61]$. The investigations from in-vitro, in-silico and in-vivo studies show that small molecules phytochemicals can ameliorate the biomarker lipoproteins indices by following several pathways.

\section{Conclusions}

It can be concluded that the principal small molecule phytochemicals of petroleum ether pod extract of Prosopis cineraria (L.) Druce possesses amelioration capacity to subside hypercholesterolemia by following the HMG-CoA reductase inhibition and free radical scavenging activity.

\section{Funding}

The study was not supported by any kind of special research grant.

\section{Acknowledgments}

This research did not receive any specific grant from funding agencies in the public, commercial, or not-for-profit sectors.

\section{Conflict of interest}

There are none of the conflicts of interest between authors regarding this publication.

\section{References}

1. Karole, S.; Shrivastava, S.; Thomas, S.; Soni, B.; Khan, S.; Dubey, J.; Dubey, S.P.; Khan, N.; Jain, D.K. Polyherbal Formulation Concept for Synergic Action: A Review. J. Drug Deliv. Ther. 2019, 9, 453-466, https://doi.org/10.22270/jddt.v9i1-s.2339.

2. Upadhyay, S.; Dixit, M. Role of polyphenols and other phytochemicals on molecular signaling. Oxid. Med. 
Cell. Longev. 2015, 2015, 1-15, https://doi.org/10.1155/2015/504253.

3. Guaadaoui, A.; Benaicha, S.; Elmajdoub, N.; Bellaoui, M.; Hamal, A. What is a bioactive compound? A combined definition for a preliminary consensus. Int. J. Nutr. Food Sci. 2014, 3, 174-179, https://doi.org/10.11648/j.ijnfs.20140303.16.

4. Francini-Pesenti, F.; Spinella, P.; Calò, L.A. Potential role of phytochemicals in metabolic syndrome prevention and therapy. Diabetes, Metab. Syndr. Obes. Targets Ther. 2019, 12, 1987-2002, https://doi.org/10.2147/DMSO.S214550.

5. Atanasov, A.G.; Waltenberger, B.; Pferschy-Wenzig, E.-M.; Linder, T.; Wawrosch, C.; Uhrin, P.; Temml, V.; Wang, L.; Schwaiger, S.; Heiss, E.H.; Rollinger, J.M.; Schuster, D.; Breuss, J.M.; Bochkov, V.; Mihovilovic, M.D.; Kopp, B.; Bauer, R.; Dirsch, V.M.; Stuppner, H. Discovery and resupply of pharmacologically active plant-derived natural products: A review. Biotechnol. Adv. 2015, 33, 1582-1614, https://doi.org/10.1016/j.biotechadv.2015.08.001.

6. Gupte, P.; Harke, S.; Deo, V.; Bhushan Shrikhande, B.; Mahajan, M.; Bhalerao, S. A clinical study to evaluate the efficacy of Herbal Formulation for Obesity (HFO-02) in overweight individuals. J. Ayurveda Integr. Med. 2019, 18, 5-8, https://doi.org/10.1016/j.jaim.2019.05.003.

7. Malik, S.; Mann, S.; Gupta, D.; Gupta, R.K. Nutraceutical Properties of Prosopis cineraria (L.) Druce Pods : A Component of “Panchkuta ." J. Pharmacogn. Phytochem. 2013, 2, 66-73.

8. Liu, Y.; Singh, D.; Nair, M.G. Pods of Khejri (Prosopis cineraria) consumed as a vegetable showed functional food properties. J. Funct. Foods 2012, 4, 116-121, https://doi.org/10.1016/j.jff.2011.08.006.

9. Talebi, M.; Talebi, M.; Samarghandian, S. Association of crocus sativus with cognitive dysfunctions and alzheimer's disease: A systematic review. Biointerface Res. Appl. Chem. 2021, 11, 7468-7492, https://doi.org/10.33263/BRIAC111.74687492.

10. Ram, H.; Krishna, A. Improvements in insulin resistance and $\beta$-cells dysfunction by ddp-4 inhibition potential of withania somnifera (L.) dunal root extract in type 2 diabetic rat. Biointerface Res. Appl. Chem. 2020, 11, 8141-8155, https://doi.org/10.33263/BRIAC111.81418155.

11. Mahdavi, A.; Bagherniya, M.; Fakheran, O.; Reiner, Ž.; Xu, S.; Sahebkar, A. Medicinal plants and bioactive natural compounds as inhibitors of HMG-CoA reductase: A literature review. BioFactors 2020, 46, 906-926, https://doi.org/10.1002/biof.1684.

12. Umar, M.I.; Javeed, A.; Ashraf, M.; Riaz, A.; Mukhtar, M.M.; Afzal, S.; Altaf, R. Polarity-based solvents extraction of opuntia dillenii and zingiber officinale for in vitro antimicrobial activities. Int. J. Food Prop. 2013, 16, 114-124, https://doi.org/10.1080/10942912.2010.517886.

13. Nabila, S.; Hamdi, B.; Zain, U.; Mohamed Djamel, M.; Messaoud, L.; Mehmet, Ö.; Salah, A.; Kamel, M.; Ahmed, M.M. LC-MS/MS Profiling of 37 Fingerprint Phytochemicals in Oenanthe fistulosa L. and its Biological Activities. Nat. Prod. J. 2021, 11, 63-73.

14. Mtewa, A.; Sesaazi, D.C.; Lampiao, F. Structural and in Silico Characterization of Small Molecules Isolated from Eichhornia crassipes. Evidence-based Complement. Altern. Med. 2020, 2020, https://doi.org/10.1155/2020/1375639.

15. Ram, H.; Jaipal, N.; Charan, J.; Kashyap, P.; Kumar, S.; Tripathi, R.; Singh, B.P.; Siddaiah, C.N.; Hashem, A.; Tabassum, B.; Abd_Allah, E.F. Phytoconstituents of an ethanolic pod extract of Prosopis cineraria triggers the inhibition of HMG-CoA reductase and the regression of atherosclerotic plaque in hypercholesterolemic rabbits. Lipids Health Dis. 2020, 19, 6, https://doi.org/10.1186/s12944-020-1188-z.

16. Reagan-Shaw, S.; Nihal, M.; Ahmad, N. Dose translation from animal to human studies revisited. FASEB J. 2008, 22, 659-661, https://doi.org/10.1096/fj.07-9574lsf.

17. Liang, G.; Kou, H.; Wang, T.; Guo, Y.; Ping, J.; Wang, H. Optimization, Validation and Application of Spectrophotometric Assay for 3-Hydroxy-3-methylglutaryl- coenzyme A Reductase Activity. Trop. J. Pharm. Res. 2015, 14, 671-677.

18. Prasongsub, W.; Pimsan, N.; Buranapattarachote, C.; Puntunee K. Anti-HMG-CoA reductase and antioxidant activities of Sacha inchi (Plukenetia volubilis L.) nutshell extract. Journal of Associated Modical Sciences. 2021, 54, 18-26, https://doi.org/10.4103/pr.pr.

19. Prasad, K. Regression of hypercholesterolemic atherosclerosis in rabbits by secoisolariciresinol diglucoside isolated from $\quad$ flaxseed. $\quad$ Atherosclerosis $\quad \mathbf{2 0 0 8 ,} \quad 197, \quad$ 34-42, https://doi.org/10.1016/j.atherosclerosis.2007.07.043.

20. Ram, H.; Jatwa, R.; Purohit, A. Antiatherosclerotic and cardioprotective potential of acacia senegal seeds in diet-induced atherosclerosis in rabbits. Biochem. Res. Int. 2014, 2014, 1-9, https://doi.org/10.1155/2014/436848.

21. Nagaraj, A.; Wilson, S.A.; Vaidyanathan, L. Anti-obesity properties of calocybe indica in zebrafishes with short-term high-fat diet induction. Biomed. Pharmacol. J. 2021, 14, 411-423, https://doi.org/10.13005/bpj/2141.

22. Tuck, M.K.; Chan, D.W.; Chia, D.; Godwin, A.K.; Grizzle, W.E.; Krueger, K.E.; Rom, W.; Sanda, M.; 
Sorbara, L.; Stass, S.; Wang, W.; Brenner, D.E. Standard Operating Procedures for Serum and Plasma Collection: Early Detection Research Network Consensus Statement Standard Operating Procedure Integration Working Group. J. Proteome Res. 2009, 8, 113-117, https://doi.org/10.1021/pr800545q.

23. Lowry OH, Rosebrough NJ, Farr AL, R.R. Protein Measurement with Folin Phenol Reagent. J. Biol. Chem. 1951, 193, 265-75.

24. Allain, C.C.; Poon, L.S.; Chan, C.S.G.; Richmond, W.; Fu, P.C. Enzymatic Determination of Total Serum Cholesterol. Clin. Chem. 1974, 20, 470-475, https://doi.org/10.1093/clinchem/20.6.724.

25. Klotzsch, S.G.; McNamara, J.R. Triglyceride measurements: A review of methods and interferences. Clin. Chem. 1990, 36, 1605-1613.

26. Hirano, T.; Nohtomi, K.; Koba, S.; Muroi, A.; Ito, Y. A simple and precise method for measuring HDLcholesterol subfractions by a single precipitation followed by homogenous HDL-cholesterol assay. J. Lipid Res. 2008, 49, 1130-1136, https://doi.org/10.1194/jlr.D700027-JLR200.

27. Nie, G.; Hou, S.; Zhang, M.; Peng, W. High TG/HDL ratio suggests a higher risk of metabolic syndrome among an elderly Chinese population: A cross-sectional study. BMJ Open 2021, 11, 1-6, https://doi.org/10.1136/bmjopen-2020-041519.

28. Bhardwaj, S.; Bhattacharjee, J.; Bhatnagar, M.K.; Tyagi, S. Atherogenic index of plasma, Castelli risk index and Atherogenic coeficent - New Parameters in assessing Cardiovascular Risk. Int. J. Pharm. Biol. Sci. 2013, $3,359-64$.

29. Weydert, C.J.; Cullen, J.J. Measurement of superoxide dismutase, catalase and glutathione peroxidase in cultured cells and tissue. Nat. Protoc. 2010, 5, 51-66, https://doi.org/10.1038/nprot.2009.197.

30. Sarian, M.N.; Ahmed, Q.U.; Mat So'Ad, S.Z.; Alhassan, A.M.; Murugesu, S.; Perumal, V.; Syed Mohamad, S.N.A.; Khatib, A.; Latip, J. Antioxidant and antidiabetic effects of flavonoids: A structure-activity relationship based study. Biomed Res. Int. 2017, 2017, 1-14, https://doi.org/10.1155/2017/8386065.

31. Beauchamp, C.; Fridovich, I. Superoxide dismutase - Improved assays and an assay applicable to acrylamide gels. Anal. Biochem. 1971, 44, 276-287, https://doi.org/10.1016/0003-2697(71)90370-8.

32. Kalkan, I.H.; Suher, M. The relationship between the level of glutathione, impairment of glucose metabolism and complications of diabetes mellitus. Pakistan J. Med. Sci. 2013, 29, 938-942.

33. Hadwan, M.H. Simple spectrophotometric assay for measuring catalase activity in biological tissues. BMC Biochem. 2018, 19, 1-8, https://doi.org/10.1186/s12858-018-0097-5.

34. Ohkawa, H.; Ohishi, N.; Yagi, K. Assay for lipid peroxides in animal tissues by thiobarbituric acid reaction. Anal. Biochem. 1979, 95, 351-358, https://doi.org/10.1016/0003-2697(79)90738-3.

35. Toppo, A.L.; Yadav, M.; Dhagat, S.; Ayothiraman, S.; Eswari, J.S. Molecular docking and admet analysis of synthetic statins for hmg-coa reductase inhibition activity. Indian J. Biochem. Biophys. 2021, 58, $127-134$.

36. Mannino, G.; Iovino, P.; Lauria, A.; Genova, T.; Asteggiano, A.; Notarbartolo, M.; Porcu, A.; Serio, G.; Chinigò, G.; Occhipinti, A.; Capuzzo, A.; Medana, C.; Munaron, L.; Gentile, C. Bioactive Triterpenes of Protium heptaphyllum Gum Resin Extract Display Cholesterol-Lowering Potential. Int. J. Mol. Sci. 2021, 22, https://doi.org/10.3390/ijms22052664.

37. Yang, B.; Xuan, S.; Ruan, Q.; Jiang, S.; Cui, H.; Zhu, L.; Luo, X.; Jin, J.; Zhao, Z. UPLC/Q-TOF-MS/MSbased metabolomics revealed the lipid-lowering effect of Ilicis Rotundae Cortex on high-fat diet induced hyperlipidemia rats. J. Ethnopharmacol. 2020, 256, 112784, https://doi.org/10.1016/J.JEP.2020.112784.

38. Assaad, H.I.; Zhou, L.; Carroll, R.J.; Wu, G. Rapid publication-ready MS-Word tables for one-way ANOVA. Springerplus 2014, 3, 1-8, https://doi.org/10.1186/2193-1801-3-474.

39. Marahatha, R.; Basnet, S.; Bhattarai, B.R.; Budhathoki, P.; Aryal, B.; Adhikari, B.; Lamichhane, G.; Poudel, D.K.; Parajuli, N. Potential natural inhibitors of xanthine oxidase and HMG-CoA reductase in cholesterol regulation: in silico analysis. BMC Complement. Med. Ther. 2021, 21, 1-11, https://doi.org/10.1186/s12906020-03162-5.

40. Parveen, B.; Parveen, A.; Parveen, R.; Ahmad, S.; Ahmad, M.; Iqbal, M. Challenges and opportunities for traditional herbal medicine today with special reference to its status in India. Ann. Phytomedicine An Int. J. 2020, 9, 97-112, https://doi.org/10.21276/ap.2020.9.2.8.

41. Rijai, L.; Kuncoro, H.; Amir, M. Chemical profile by LC-MS/MS and some bioactivities from leafs of kolowe (Chydenanthus excelsus): A wild and rare plant from indonesia. J. Pharm. Sci. Res. 2017, 9, 111-118.

42. Ahmad, S.; Zahiruddin, S.; Parveen, B.; Basist, P.; Parveen, A.; Gaurav; Parveen, R.; Ahmad, M. Indian Medicinal Plants and Formulations and Their Potential Against COVID-19-Preclinical and Clinical Research. Front. Pharmacol. 2021, 11, 1-34, https://doi.org/10.3389/fphar.2020.578970.

43. Brahmachari, G.; Basak, A.; O’Reilly, P.; Ozed-Williams, B.; Basak, S. Small Molecule Phytocompounds as Promoters of LDL-receptor and PCSK9 Inhibition: Potential Role as Non-statin Based Cardio-protective Agents. In Cardioprotective Natural Products; https://doi.org/10.1142/9789813231160_0008.

44. Othman, Z.A.; Ghazali, W.S.W.; Noordin, L.; Yusof, N.A.M.; Mohamed, M. Phenolic compounds and the 
anti-atherogenic effect of bee bread in high-fat diet-induced obese rats. Antioxidants 2020, 9, 1-12, https://doi.org/10.3390/antiox9010033.

45. Chang, H.-Y.; Wu, J.-R.; Gao, W.-Y.; Lin, H.-R.; Chen, P.-Y.; Chen, C.-I.; Wu, M.-J.; Yen, J.-H. The Cholesterol-Modulating Effect of Methanol Extract of Pigeon Pea (Cajanus cajan (L.) Millsp.) Leaves on Regulating LDLR and PCSK9 Expression in HepG2 Cells. Molecules 2019, 24, 493, 1-15, https://doi.org/10.3390/molecules24030493.

46. Ravnskov, U.; de Lorgeril, M.; Kendrick, M.; Diamond, D.M. Serious flaws in targeting LDL-C reduction in the management of cardiovascular disease in familial hypercholesterolemia. Expert Rev. Clin. Pharmacol. 2021, 14, 405-406, https://doi.org/10.1080/17512433.2021.1889368.

47. Chandran, R.; Primelazhagan, T.; Shanmugam, S.; Thankarajan, S. Antidiabetic activity of Syzygium calophyllifolium in Streptozotocin-Nicotinamide induced Type-2 diabetic rats. Biomed. Pharmacother. 2016, 82, 547-554, https://doi.org/10.1016/j.biopha.2016.05.036.

48. Raafat, K. Identification of phytochemicals from North African plants for treating Alzheimer's diseases and of their molecular targets by in silico network pharmacology approach. J. Tradit. Complement. Med. 2021, 11, 268-278, https://doi.org/10.1016/j.jtcme.2020.08.002.

49. Jasmine, J.M.; Vanaja, R. In silico analysis of phytochemical compounds for optimizing the inhibitors of HMG CoA reductase. J. Appl. Pharm. Sci. 2013, 3, 43-47, https://doi.org/10.7324/JAPS.2013.3908.

50. Lin, S.H.; Huang, K.J.; Weng, C.F.; Shiuan, D. Exploration of natural product ingredients as inhibitors of human HMG-CoA reductase through structure-based virtual screening. Drug Des. Devel. Ther. 2015, 9, 3313-3324, https://doi.org/10.2147/DDDT.S84641.

51. Ray, K.K.; Bays, H.E.; Catapano, A.L.; Lalwani, N.D.; Bloedon, L.T.; Sterling, L.R.; Robinson, P.L.; Ballantyne, C.M. Safety and Efficacy of Bempedoic Acid to Reduce LDL Cholesterol. N. Engl. J. Med. 2019, 380, 1022-1032, https://doi.org/10.1056/NEJMoa1803917.

52. Turner, S.; Voogt, J.; Davidson, M.; Glass, A.; Killion, S.; Decaris, J.; Mohammed, H.; Minehira, K.; Boban, D.; Murphy, E. Measurement of reverse cholesterol transport pathways in humans: in vivo rates of free cholesterol efflux, esterification, and excretion. Journal of the American Heart Association 2012, 1, e001826, https://doi.org/10.1161/jaha.112.001826.

53. Frohlich, J.; Dobiášová, M. Fractional Esterification Rate of Cholesterol and Ratio of Triglycerides to HDLCholesterol Are Powerful Predictors of Positive Findings on Coronary Angiography. Clin. Chem. 2003, 49, 1873-1880, https://doi.org/10.1373/clinchem.2003.022558.

54. Alamu, E.O.; Maziya-Dixon, B.; Menkir, A.; Irondi, E.A.; Olaofe, O. Bioactive Composition and Free Radical Scavenging Activity of Fresh Orange Maize Hybrids: Impacts of Genotype, Maturity Stages, and Processing Methods. Front. Nutr. 2021, 8, 1-10, https://doi.org/10.3389/fnut.2021.640563.

55. Yamashita, S.; Ruscica, M.; Macchi, C.; Corsini, A.; Matsuzawa, Y.; Sirtori, C.R. Cholesteryl ester transfer protein: An enigmatic pharmacology - Antagonists and agonists. Atherosclerosis 2018, 278, 286-298, https://doi.org/10.1016/j.atherosclerosis.2018.09.035.

56. Ayu Agbecha, A.E.A. Atherogenic indices and smoking habits in cigarette smokers. Environ. Dis. 2018, 3 , $38-44$.

57. Li, Y.W.; Kao, T.W.; Chang, P.K.; Chen, W.L.; Wu, L.W. Atherogenic index of plasma as predictors for metabolic syndrome, hypertension and diabetes mellitus in Taiwan citizens: a 9-year longitudinal study. Sci. Rep. 2021, 11, 1-8, https://doi.org/10.1038/s41598-021-89307-z.

58. Ibrahim, A.; Shafie, N.H.; Esa, N.M.; Shafie, S.R.; Bahari, H.; Abdullah, M.A. Mikania micrantha extract inhibits hmg-coa reductase and acat2 and ameliorates hypercholesterolemia and lipid peroxidation in high cholesterol-fed rats. Nutrients 2020, 12, 1-16, https://doi.org/10.3390/nu12103077.

59. More, G.K.; Makola, R.T. In-vitro analysis of free radical scavenging activities and suppression of LPSinduced ROS production in macrophage cells by Solanum sisymbriifolium extracts. Sci. Rep. 2020, 10, 1-9, https://doi.org/10.1038/s41598-020-63491-w.

60. Rahman, K. Studies on free radicals, antioxidants, and co-factors. Clin. Interv. Aging 2007, 2, $219-236$.

61. Ibrahim, H.R.; Nanbu, F.; Miyata, T. Potent antioxidant peptides derived from honey major protein enhance tolerance of eukaryotic cells toward oxidative stress. Food Prod. Process. Nutr. 2021, 3, 1-10, https://doi.org/10.1186/s43014-021-00052-2. 